\title{
The effect of conjugated linoleic acid supplements on oxidative and antioxidative status of dairy cows
}

\author{
N. Hanschke, ${ }^{* 1}$ M. Kankofer,† L. Ruda, ${ }^{*}$ M. Höltershinken, ${ }^{*}$ U. Meyer,ł J. Frank,§ S. Dänicke,‡ and J. Rehage* \\ ${ }^{*}$ Clinic for Cattle, University of Veterinary Medicine, Foundation, 30173, Hannover, Germany \\ †University of Life Sciences, 20-033, Lublin, Poland \\ łInstitute of Animal Nutrition, Friedrich-Loeffler-Institut, Federal Research Institute for Animal Health, 38116, Braunschweig, Germany \\ §Institute of Biological Chemistry and Nutrition, University of Hohenheim, 70599 Stuttgart, Germany
}

\begin{abstract}
Dairy cows develop frequently negative energy balance around parturition and in early lactation, resulting in excessive mobilization of body fat and subsequently in increased risk of ketosis and other diseases. Dietary conjugated linoleic acid (CLA) supplements are used in dairy cows mainly for their depressing effect on milk fat content, but are also proposed to have antioxidative properties. As negative energy balance is associated with oxidative stress, which is also assumed to contribute to disease development, the present study was conducted to examine effects of CLA on oxidative and antioxidative status of lactating dairy cows. German Holstein cows (primiparous $\mathrm{n}=13$, multiparous $\mathrm{n}=32$ ) were divided into 3 dietary treatment groups receiving $100 \mathrm{~g} / \mathrm{d}$ of control fat supplement, containing $87 \%$ stearic acid $(\mathrm{CON} ; \mathrm{n}=14), 50 \mathrm{~g} / \mathrm{d}$ of control fat supplement and $50 \mathrm{~g} / \mathrm{d}$ of CLA supplement (CLA 50; $\mathrm{n}=15$ ), or $100 \mathrm{~g} / \mathrm{d}$ of CLA supplement (CLA 100; $\mathrm{n}=16$ ). The CLA supplement was lipid-encapsulated and contained $12 \%$ of trans-10, cis- 12 CLA and cis-9,trans-11 CLA each. Supplementation took place between d 1 and 182 postpartum; d 182 until 252 postpartum served as a depletion period. Blood was sampled at d $-21,1,21,70,105,140,182,224$, and 252 relative to calving. The antioxidative status was determined using the ferric-reducing ability of plasma, $\alpha$-tocopherol, $\alpha$-tocopherol-to-cholesterol mass ratio, and retinol. For determination of oxidative status concentrations of hydroperoxides, thiobarbituric acidreactive substances (TBARS), $N^{\prime}$-formylkynurenine, and bityrosine were measured. Mixed models of fixed and random effects with repeated measures were used to evaluate period 1 (d -21 to 140 ) and 2 (d 182-252) separately. Cows showed increased oxidative stress and lipid peroxidation during the periparturient period
\end{abstract}

Received November 26, 2015.

Accepted June 24, 2016.

${ }^{1}$ Corresponding author: nina.hanschke@tiho-hannover.de in terms of increased serum concentrations of hydroperoxides and TBARS, which decreased throughout lactation. During period 1, the supplemented cows had lower TBARS concentrations, which was not detectable in period 2. The other determined parameters were not affected by CLA supplementation. The obtained results show that dietary CLA supplementation in the chosen dosage, formulation, and application period had a marginal antioxidative effect in terms of lipid peroxidation in lactating dairy cows.

Key words: conjugated linoleic acid, dairy cow, oxidative stress, antioxidant

\section{INTRODUCTION}

Around parturition and in early lactation, negative energy balance is frequently found in dairy cows because of an imbalance between energy intake and energy demands for fetal growth and milk production (Goff and Horst, 1997). Negative energy balance is compensated by mobilization of body energy reserves, in particular fat from adipose tissues. Excessive lipomobilization may lead to health disorders, such as ketosis and fatty liver (Drackley, 1999; Bobe et al., 2004).

The enhanced metabolism of the periparturient cow leads to a rise in production oxidizing agents, including oxygen radicals and certain nonradicals, referred to as reactive oxygen species (ROS; Halliwell, 1996; Bionaz et al., 2007). During the periparturient period, free radicals and ROS, such as the strongly oxidizing hydroxyl radical, are formed under physiological and pathological conditions in enzymatic pathways of mitochondria or the respiratory burst of immune defense (Osorio et al., 2014). Reactive oxygen species readily attack biological macromolecules such as lipids and proteins, including enzymes or carrier proteins, causing structural changes and loss of function to the point of cellular dysfunction and apoptosis (Scherer and Deamer, 1986; Stewart, 1994).

To inhibit impaired biological function due to damage to macromolecules by ROS, living organ- 
isms have developed a complex antioxidant defense system, divided into low-molecular mass antioxidants and antioxidative enzymes (Locher et al., 2011). Lowmolecular mass antioxidants include the lipid-soluble $\alpha$-tocopherol, protecting cell membranes from lipid peroxidation by scavenging free radicals ( $\mathrm{Yu}, 2001$ ). Further low-molecular mass antioxidants are ascorbic acid and $\beta$-carotene, which are able to quench singlet oxygen and peroxyl radicals and enhance the antioxidative effect of $\alpha$-tocopherol (Palozza and Krinsky, 1991, 1992). Retinol only shows antioxidant activity in vitro, but not in vivo (Azzi et al., 2004); however, high retinol concentrations have been shown to reduce the risk of disease in dairy cows (LeBlanc et al., 2004).

Increased lipid peroxidation (Bernabucci et al., 2005; Castillo et al., 2005), decreased plasma antioxidant concentrations (Bouwstra et al., 2010b), and low antioxidative enzyme activity (Gaál et al., 2006) have been established as typical findings in blood samples of periparturient dairy cows. This imbalance between ROS and antioxidants favoring the first and disfavoring the latter is commonly referred to as oxidative stress (Sies, 1993). Excessive amounts of ROS during oxidative stress damage cellular membranes or other components, leading to changes in physiological pathways and even cause pathology (Miller et al., 1993). Correlations between decreased antioxidants, oxidative stress, and peripartal production diseases, such as mastitis, retained fetal membranes, and reduced fertility, have been discussed (LeBlanc et al., 2004; Kankofer et al., 2010; Heidarpour et al., 2012).

Mixtures of trans-10,cis-12 and cis-9,trans-11 isomers of CLA were repeatedly investigated regarding their effect on improving negative energy balance in periparturient and early-lactation cows. The hypothesis was that CLA may reduce energy expenditure for milk production due to reduced de novo synthesis of milk fat caused by trans-10,cis-12 CLA (Baumgard et al., 2000). However, recent research has revealed inconsistent results of CLA supplements on energy balance (Castañeda-Gutiérrez et al., 2005; Odens et al., 2007; Hötger et al., 2013). Several studies revealed an increase in overall milk yield next to the milk fat depression (Giesy et al., 2002; Bernal-Santos et al., 2003). These results suggest increased milk yield may countermand the CLA-induced milk fat depression concerning energy balance.

Antioxidative effects have been shown for different CLA isomers in vitro (Leung and Liu, 2000; Basiricò et al., 2015) and in vivo in rats (Ip et al., 1991), mice (Ha et al., 1990), and hens (Qi et al., 2011). Conversely, further in vitro studies delivered contradicting results and showed a possible pro-oxidative effect of CLA (van den Berg et al., 1995; Chen et al., 1997); pro-oxidative properties of CLA have been described in human trials (Basu et al., 2000; Risérus, 2002). The aim of the current study was to investigate effects of long-term supplementation of a commercial CLA isomer mixture, containing trans-10,cis-12 CLA and cis-9,trans-11 CLA in equal amounts, on the antioxidative and oxidative profiles of peripartal and lactating dairy cows.

\section{MATERIALS AND METHODS}

\section{Animals and Feeding}

The trial was conducted in 32 multiparous (second lactation: $\mathrm{n}=22$; third lactation $\mathrm{n}=5$; fourth lactation $\mathrm{n}=5$ ) and 13 primiparous German Holstein cows at the Institute of Animal Nutrition of the FriedrichLoeffler-Institut. Details on housing, feeding, CLA supplements, and production parameters of studied cows in this trial are already presented by Pappritz et al. (2011b). Briefly, animals, housed in a freestall, were separated into 3 groups taking into consideration the BW (multiparous from $483-655 \mathrm{~kg}$, primiparous from $391-522 \mathrm{~kg}$ ), the number of lactations, and the milk yield during the last lactation.

Before parturition, all animals were pasture fed: primiparous animals for 3 mo before calving and multiparous animals up to 5 wk between dry off and study start. Three weeks antepartum, all animals were housed and received the same TMR diet, with $63 \%$ silage $(60 \%$ maize and $40 \%$ grass silage) and $37 \%$ concentrate on a DM basis until parturition. After parturition, animals were assigned either to a control group $(\mathbf{C O N})$ or 1 of 2 treatment groups (CLA 50 and CLA 100) and fed a partial mixed ration (PMR) ad libitum provided in troughs suitable for measurement of individual feed intake (TYPE RIC, Insentec B.V., Marknesse, the Netherlands). The PMR contained the same amounts of silage and concentrate as TMR. Additionally, all animals received $4 \mathrm{~kg}$ of concentrate, which included the fat supplements between d 1 and 182 postpartum, via transponder-controlled feeding stations. Included in the concentrate control cows received $100 \mathrm{~g}$ of a commercial fat supplement (Silafat, BASF SE, Ludwigshafen, Germany) and cows of the CLA 100 group received $100 \mathrm{~g}$ of a commercial CLA product (Lutrell Pure, BASF SE); cows of the CLA 50 group were fed $50 \mathrm{~g}$ of the control fat supplement and $50 \mathrm{~g}$ of the CLA product.

The CLA fat supplement contained $11.9 \%$ of trans10, cis-12 CLA and 12.0\% cis-9,trans-11 CLA (Pappritz et al., 2011b), whereas the control supplement contained $87 \%$ of stearic acid (C18:0). In both supplements, $11 \%$ 
of total weight were from the coat, which was made up of palmitic acid and stearic acid, both linked to glycerine and was used to protect CLA supplements from rumen biohydrogenation (Pappritz et al., 2011a). Water was available ad libitum.

\section{Sampling}

Blood samples were taken on $d-21$ (mean \pm SD: $-21 \pm 4$ ) before calving and on d 1, 21, 70, 105, 140, 182, 224, and 252 after parturition from the jugular vein into a $10-\mathrm{mL}$ serum tube and a $4-\mathrm{mL}$ heparincoated tube. Blood was centrifuged immediately and aliquots of serum or plasma were stored at $-80^{\circ} \mathrm{C}$.

\section{Analytical Methods}

Protein. The protein content was measured in both serum and plasma samples by the biuret method (Gornall et al., 1949) using commercial assay kits (Liquick Cor - Total Protein, Ref $2-237$, PZ Cormay S.A., Lublin, Poland).

Cholesterol and Fatty Acids. The serum cholesterol concentrations were analyzed in an automated procedure using a Cobas Mira Plus System (Roche Diagnostic, Mannheim, Germany), based on a spectrophotometric assay. The control was Seronorm Human (Sero AS, Billingstad, Norway). Plasma fatty acids were determined by enzymatic analysis using a commercial kit (Wako Chemicals GmbH, Neuss, Germany).

$\alpha$-Tocopherol and Retinol. $\alpha$-Tocopherol and retinol were analyzed in saponified samples using an HPLC system (LC10-AT and RF-551, Shimadzu, Kyoto, Japan) according to the method described by (Rammell et al., 1983). Two standards were used (Chromosystems Instruments \& Chemicals GmbH, Gräfelfing, Germany).

Tocopherol isomers, including $\alpha$-tocopherol, are carried in the blood stream bound to lipoproteins containing cholesterol. A shortage of carrier molecules, due to effects of lactation stage and lipomobilization, may dissemble low $\alpha$-tocopherol concentrations in the blood stream. To avoid lactational fluctuation of cholesterol affecting $\alpha$-tocopherol measurements, the $\alpha$-tocopherolto-cholesterol mass ratio ( $\mathbf{\alpha} \mathbf{T}: \mathbf{C})$ was calculated (Herdt and Smith, 1996).

Ferric-Reducing Ability of Plasma. The total antioxidative capacity was determined by photometric measurement based on the ferric-reducing ability of plasma (FRAP), slightly modified from the method described by Benzie and Strain (1996). The change in absorbance over 10 min was directly related to the total reducing capacity of antioxidants in the plasma sample, the working agent alone served as control; Fe (II) was used as standard.

Hydroperoxides. Oxygen-centered radicals abstract hydrogen atoms from neighboring molecules, leading to formation of alcohols and hydroperoxides (Alberti et al., 2000). Hydroperoxides decompose to form alkoxy and peroxyl radicals (Hiatt and Irwin, 1968). For this indirect measurement of hydroperoxides in the sample, described by Alberti et al. (2000), the serum was added to acetate buffer ( $\mathrm{pH}$ 4.8) and a solution of $N, N$,diethyl-para-phenylene diamine (DEPPD; Cat 16.834-3, Sigma-Aldrich, Steinheim, Germany). The alkoxy and peroxyl radicals present in the sample react with DEPPD to form the radical cation of DEPPD, which was photometrically detected at $505 \mathrm{~nm}$ against a control sample in which distilled water replaced the serum; $\mathrm{H}_{2} \mathrm{O}_{2}$ served as standard.

Thiobarbituric Acid-Reactive Substances. For the determination of thiobarbituric acid-reactive substances (TBARS), the photometric method described by Ledwozyw et al. (1986) using thiobarbituric acid was applied. Malondialdehyde (MDA) served as standard.

$N^{\prime}$-Formylkynurenine and Bityrosine. The 2 indicators of protein peroxidation, bityrosine and $N^{\prime}$ formylkynurenine, were both determined by spectrofluorometry, as described by Rice-Evans et al. (1991). Plasma was excited by light, in case of bityrosine at $325 \mathrm{~nm}$ and emission was read at $420 \mathrm{~nm}$. For measurement of $N^{\prime}$-formylkynurenine excitation wavelength was $360 \mathrm{~nm}$ and emission was read at $454 \mathrm{~nm}$. The spectrofluorometer (Jasco, Tokyo, Japan) was standardized to 100 deflections with quinine sulfate dissolved in sulfuric acid. Results were expressed as milligrams per grams of protein to avoid fluctuation of plasma protein influencing detected concentrations of bityrosine and $N^{\prime}$-formylkynurenine.

\section{Statistical Analysis}

Statistics were calculated with SAS version 9.3 TS for Windows (SAS Institute Inc., Cary, NC). Results were tested for normal distribution, if data deviated significantly from normal distribution the logarithm to the base 10 was used for further statistical evaluation (fatty acids, FRAP, TBARS, $\alpha$-tocopherol, and $\alpha-T: C)$. Period 1 was between $d-21$ and 140 , whereas the depletion period (d 182-252) was referred to as period 2. Both periods were analyzed separately.

Mixed models of fixed and random effects with repeated measures were used for statistical evaluation. The covariance structure was chosen according to Bayesian information criterion value for each parameter and period. Treatment group (CON, CLA 50, 
CLA 100) and lactation number (Lact; multiparous, primiparous) were used as fixed effects. Days in milk and individual animal were added as repeated effects. Interactions of effects (group $\times$ DIM, group $\times$ Lact) were also considered in the model. For the analysis of period 1, the base value was added to fixed effects to avoid incidental differences between groups affecting the results. Multiple comparisons of means were adjusted using the Tukey-Kramer method.

Results are presented as least squares means with standard error of means, or in the case of data that was not normally distributed as medians with 5th and 95th percentiles. A $P$-value $<0.05$ was considered significant; $P$-values between 0.05 and 0.1 were referred to as a trend.

\section{RESULTS}

\section{Effects of DIM on Antioxidative and Oxidative Status}

Time-dependent changes in antioxidative status were found for all antioxidative parameters measured during period 1, as shown in Table 1. In animals of the CON and CLA 100 groups, the mean FRAP values decreased toward parturition and increased postpartum, similar patterns were observed for $\alpha$-tocopherol and retinol in animals of all groups. During period 2 animals of all groups delivered similar results. The FRAP values decreased significantly $(P<0.001)$, whereas $\alpha$-tocopherol and retinol concentrations showed a trend to decrease ( $P=0.085$ and $P=0.051$, respectively). The $\alpha-\mathrm{T}: \mathrm{C}$, on the other hand, decreased toward parturition and remained constant during later stages of lactation.

Parameters of oxidative status all varied significantly with DIM during both study periods, as shown in Table 2. The observed pattern for protein peroxidation followed the inverse pattern of hydroperoxides and TBARS during period 1. During period 1 the mean concentration of TBARS $(P<0.001)$ and hydroperoxides $(P<0.001)$ increased significantly toward parturition and decreased over the course of lactation, whereas protein peroxidation parameters, $N^{\prime}$-formylkynurenine $(P<0.001)$ and bityrosine $(P<0.001)$, decreased toward parturition and increased during the postpartum period. During the depletion period all oxidative parameters varied significantly, with the same opposing pattern. After the end of supplementation at d 182, hydroperoxides $(P<0.001)$ and TBARS $(P<0.001)$ significantly increased, whereas $N^{\prime}$-formylkynurenine $(P=0.002)$ and bityrosine $(P<0.001)$ decreased.

During period 1 , plasma fatty acids increased significantly toward d 1 and decreased during lactation $(P$ $<0.001$; Table 3). Between d 182 and 224, fatty acid concentrations increased again, resulting in an overall time effect during period $2(P=0.015)$.

\section{Effects of CLA on Antioxidative and Oxidative Status}

No significant effects of CLA supplementation on antioxidative status were observed during the present trial (Table 2). We found a significant group effect for TBARS concentrations during period $1(P=0.016)$, with the cows of the CON group exhibiting higher mean TBARS concentrations than supplemented animals of the CLA 50 and CLA 100 groups. A group trend was observed for mean bityrosine concentrations, where supplemented animals showed higher serum concentrations $(P=0.084)$.

\section{Effects of Lactation on Antioxidative and Oxidative Status}

The overall antioxidative status, measured as FRAP, showed a significant DIM $\times$ Lact interaction during period $1(P<0.001$; Figure 1a). During this period, primiparous animals tended to have higher mean $\alpha$-tocopherol concentrations than multiparous animals $(P=0.074 ;$ Figure 1b). For $\alpha$-tocopherol the difference became more apparent in period 2 , where primiparous animals had significantly higher mean $\alpha$-tocopherol serum concentrations than multiparous animals $(P<$ $0.001)$. The $\alpha-\mathrm{T}: \mathrm{C}$ was influenced accordingly by lactation, as primiparous animals showed a significantly higher ratio than multiparous animals in both periods $(P<0.001$; Figure 1c $)$.

Oxidative status differed between multiparous and primiparous animals during both periods. During period 1, we noted a significant DIM $\times$ Lact interaction for hydroperoxides $(P<0.001$; Figure $1 \mathrm{~d})$ and a trend for a DIM $\times$ Lact interaction for TBARS $(P=0.052$; Figure 1e). During period 2, primiparous animals had significantly lower mean hydroperoxide concentrations than multiparous animals $(P=0.016)$. Primiparous animals had significantly lower plasma fatty acid concentrations than multiparous animals during period 1 $(P<0.001 ;$ Figure 1f $)$; this difference was not detectable in period 2 .

\section{DISCUSSION}

\section{Lactation}

After parturition, with the onset of lactation, metabolism rapidly intensifies and increased mitochondrial activity may lead to overproduction of ROS (Albera and Kankofer, 2011). On the other hand, the maternal 
HANSCHKE ET AL.




CONJUGATED LINOLEIC ACID AND OXIDATIVE STRESS

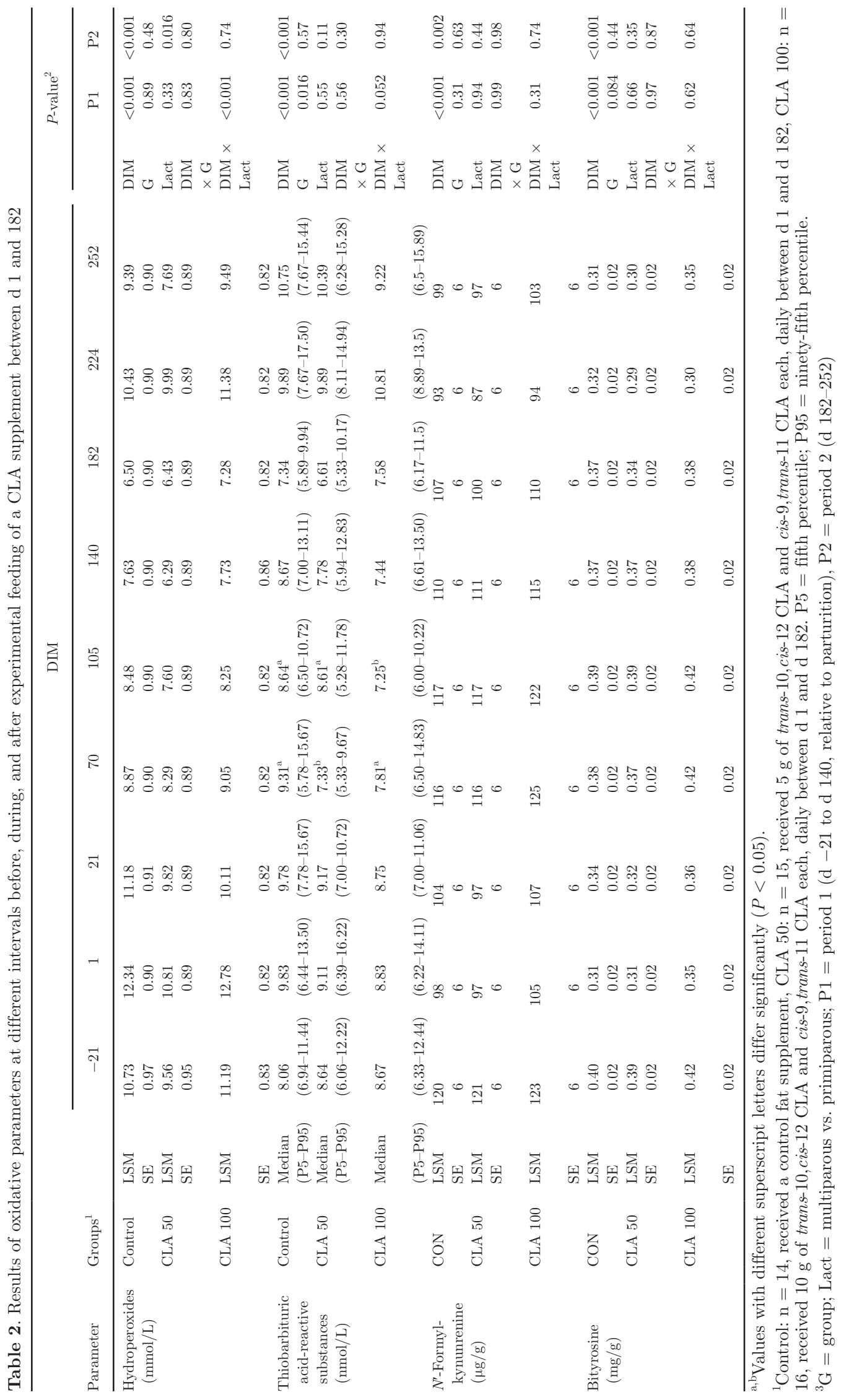






cow experiences a drastic decrease in antioxidative substances due to loss to colostrum production (Goff and Stabel, 1990).

Antioxidants may inhibit damage to molecules and cells by inhibiting production of radicals or ROS, scavenging them from biological systems, or disarming them to less reactive substances (Cadenas, 1997). The FRAP is an index of the antioxidative potential of plasma, influenced to $60 \%$ by uric acid (Benzie and Strain, 1996), but also by various other antioxidants in the plasma (Bouwstra et al., 2010a). In the present study a decreased peripartal antioxidative potential was observed, in terms of FRAP values, which were lower during the periparturient period and early than mid lactation values, in agreement with results of Gaál et al. (2006) and (Bouwstra et al., 2010a).

$\alpha$-Tocopherol is the most abundant of 8 isomers of vitamin E in dairy cows (Frank et al., 2012; Sadri et al., 2015). As a lipid-soluble antioxidant it protects cell membranes against oxidative attack. Retinol is able to quench singlet oxygen and may improve antioxidant activity of $\alpha$-tocopherol (Krinsky, 1989). $\alpha$-Tocopherol and retinol serum concentrations decreased significantly during the dry period toward parturition, as observed previously (Politis et al., 2012). The significant decrease of the $\alpha-T: C$ at parturition, by about $40 \%$ compared with $\mathrm{d}-21$, and steady levels thereafter until the end of the study period are in agreement with results of previous trials (Herdt and Smith, 1996; Politis et al., 2012). According to Weiss et al. (1992), this antepartum decrease of the $\alpha-\mathrm{T}$ : $\mathrm{C}$ indicates selective secretion of $\alpha$-tocopherol into colostrum by the mammary gland.

The significant increase of hydroperoxide concentrations toward parturition during the present study, also shown in the results of Kankofer et al. (2010) and Politis et al. (2012), indicates that dairy cows are exposed to increased oxidative stress at parturition. Enhanced fat mobilization, indicated by increased plasma fatty acids, leads to increased production of ROS in the respiratory chain in mitochondria (Miller et al., 1993; Muller, 2000). Oxidative processes in the liver as a consequence of lipomobilization in periparturient dairy cows have been shown to decrease activity of antioxidative enzymes, resulting in high ROS concentrations (Turk et al., 2005). Further ROS production may also result from a challenged immune system, which responds with an enhanced respiratory burst of different ROS, such as the superoxide radical (Babior, 1987). Increased production of ROS leads to an imbalance between formation and detoxification of oxygen radicals (Lohrke et al., 2004) and excess radicals attack fatty acids, causing lipid peroxidation (Halliwell and Chirico, 1993). Positive correlations between serum fatty acids and MDA and between fatty acids and ROS have been 

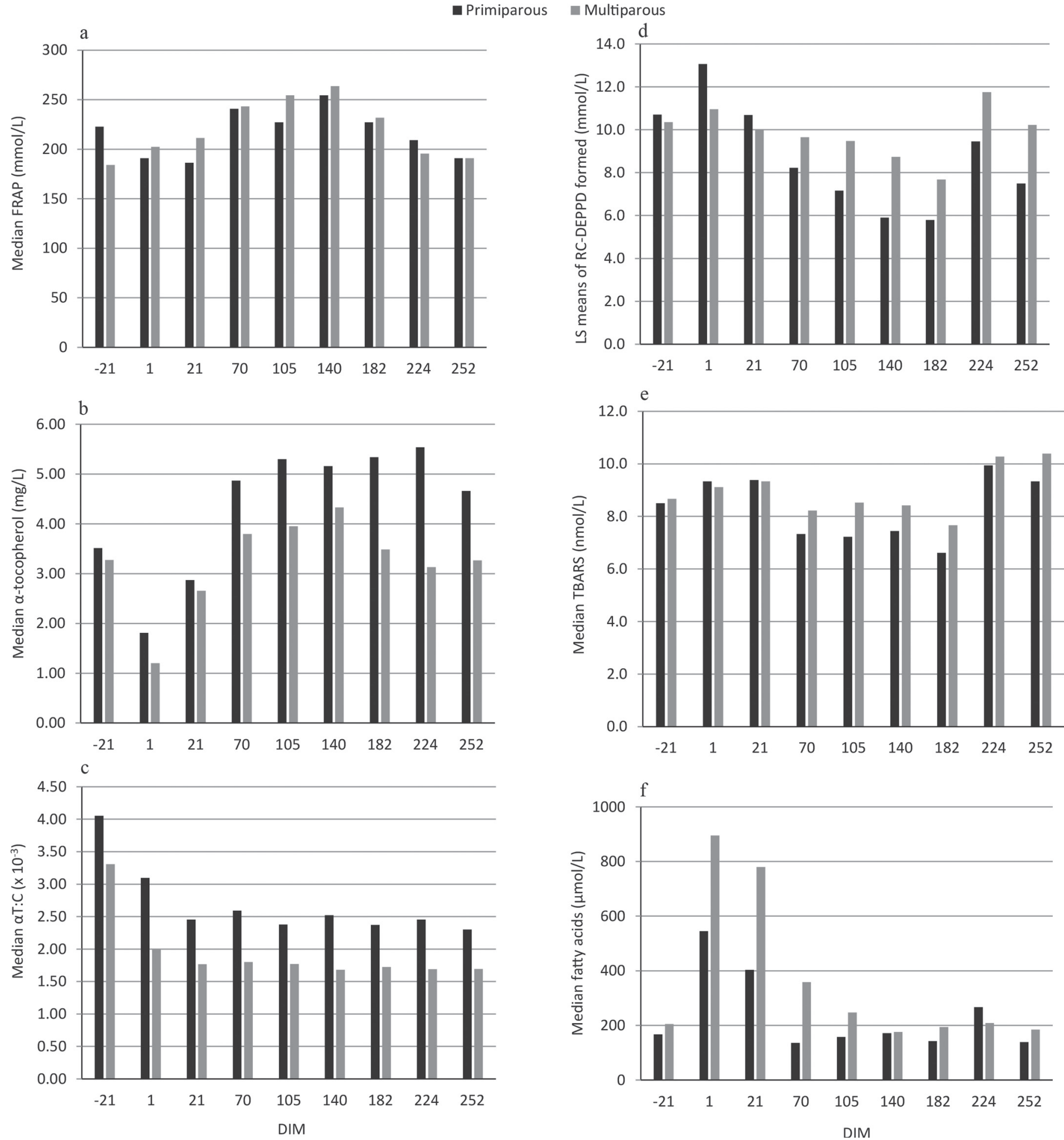

Figure 1. Median ferric-reducing ability of plasma (FRAP) concentrations (a); median $\alpha$-tocopherol serum concentrations (b); median $\alpha$-tocopherol-to-cholesterol mass ratio $(\alpha-\mathrm{T}: \mathrm{C} ; \mathrm{c})$; LSM of the radical cation $(\mathrm{RC})$ of $N, N$,diethyl-para-phenylene diamine (DEPPD) formed, representing the amount of hydroperoxides present in the sample (d); median thiobarbituric acid-reactive substances (TBARS; e); and median plasma fatty acids (f) of multiparous and primiparous cows during the periparturient period and lactation (d -21 to 252 relative to calving). 
shown for dairy goats (Radin et al., 2015) and dairy cows (Bernabucci et al., 2005), respectively.

However, the peak of serum hydroperoxides at $\mathrm{d} 1$ (Figure 1d), and thus oxidative stress, gives rise to the idea that parturition itself may cause oxidative stress. Increased circulating ROS may originate from intensive muscular activity during labor (Chiaradia et al., 1998; Powers and Jackson, 2008), as reported recently in a human trial (Hung et al., 2011), or from the proinflammatory response following the release of prostaglandin $\mathrm{F}$ or prostaglandin $\mathrm{E}$ from the uterus during calving or infection, respectively (LeBlanc, 2012; Osorio et al., 2014).

Strong oxidizing agents, such as the hydroxide radical, attack lipids and cause a chain reaction. Unstable lipid hydroperoxides, formed during lipid peroxidation, decompose to peroxyl and alkoxy radicals, which are further hydrolyzed to a mixture of toxic aldehydes including MDA (Armstrong and Browne, 1994; Barrera, 2012). Malondialdehyde among other of the aldehydes formed reacts with thiobarbituric acid and is thus detectable as TBARS. Median TBARS concentrations followed a similar pattern to the hydroperoxide concentrations during the periparturient period and lactation, revealing increased lipid peroxidation at parturition, as reported before (Bernabucci et al., 2005; Gaál et al., 2006).

In an oxidative environment, free radicals or hydroperoxides, such as lipid hydroperoxides, may damage proteins either by a chain reaction resulting in protein fragmentation or oxidation of AA residues (Rahmanto et al., 2010). Aromatic AA such as Trp are readily oxidized; for instance, Trp is oxidized to $N^{\prime}$-formylkynurenine and different isomers of hydroxytryptophan, which occur physiologically in limited amounts (Maskos et al., 1992). Oxidation of Tyr results in formation of a tyrosyl radical (Giulivi et al., 2003), 2 of these tyrosyl radicals react to form an intra- or interprotein crosslink, named bityrosine or sometimes referred to as dityrosine (Heinecke et al., 1993; Huggins et al., 1993). Bityrosine production in vitro showed a direct and quantitative relationship to the amount of radicals present in the sample (Morzel et al., 2006) and has been referred to as a sensitive marker for protein oxidation (Davies et al., 1999; Tatarková et al., 2005).

Bityrosine and $N^{\prime}$-formylkynurenine followed a plasma concentration pattern nearly opposite to mean hydroperoxide and TBARS concentrations during the periparturient period and in early lactation. It appears that, despite the observed antepartum decline in serum $\alpha$-tocopherol and retinol concentrations, the antioxidative potential measured as FRAP was still strong enough to protect Trp and Tyr from oxidative attack (Kankofer et al., 2010). Davies et al. (1987) showed that uric acid could effectively protect Trp and, to some extent, prevent bityrosine formation. Uric acid is the dominant factor contributing to overall FRAP.

\section{CLA}

We found no significant differences between groups for mean serum hydroperoxides as an indicator for oxidative stress. Lipid peroxidation, in terms of TBARS concentrations, differed significantly during period 1 , with CLA-supplemented animals exhibiting lower concentrations than control animals. Basiricò et al. (2015) recently reported a similar effect in an in vitro model using bovine mammary epithelial cells and concluded that CLA-induced de novo synthesis of glutathione through enhanced $\gamma$-glutamylcysteine ligase activity effectively protected cells from oxidative damage. As glutathione was not analyzed in the present study, this theory should be expanded from cell cultures to the animal model in further studies.

Antioxidative effects of CLA on TBARS concentrations have also been described in rats, broiler chicks, and laying hens (Santos-Zago et al., 2007; Zhang et al., 2008; Qi et al., 2011). Livisay et al. (2000) pronounced another possible explanation for the putative antioxidative effect of CLA, based on the incorporation of CLA into body fats and replacing other PUFA (Banni et al., 1998, 1999). This incorporation of CLA into body lipids induces changes in lipid fatty acid profiles, depending on the dietary CLA content, thus reducing proportions of other lipid PUFA, in particular arachidonic acid (Cantwell et al., 1999). Malondialdehyde and, thus, TBARS are formed from oxidation of fatty acids with 3 or more double bonds, including arachidonic acid (Janero, 1990). Decreasing proportions of these PUFA may reduce the absolute amount of MDA produced by lipid peroxidation without reducing relative lipid peroxidative activity, thus dissembling an antioxidative effect of CLA (Livisay et al., 2000).

In studies on rats and hens (Banni et al., 1999; Livisay et al., 2000; Qi et al., 2011), which revealed a significant change in fatty acid profiles of body lipids due to CLA supplementation, the dietary CLA content was about $2 \%$. In the present study the dietary content of the CLA product was about 0.25 to $0.5 \%$ on a DM basis, corresponding a dietary content of about $0.05 \%$ of each isomer. An equal dose of the same commercial, lipid-encapsulated CLA supplement was used in a follow-up study to the present study by Pappritz et al. (2011a), and results showed a duodenal availability of CLA isomers of only $16 \%$ in the CLA 50 group and $5 \%$ in the CLA 100 group. This suggests that, despite rumen protection using hydrogenated vegetable fats, a high proportion of the supplemented CLA was hy- 
drogenated by rumen bacteria and was therefore not available. This assumption is supported by increasing amounts of 18:1 fatty acids, the hydrogenated form of 18:2 CLA, in the feces of CLA supplemented animals. Pappritz et al. (2011a) also found that 35 to $50 \%$ of available CLA isomers were transferred into milk. The chosen dosage of the commercial CLA product had only marginal effects on fatty acids profiles in various organ lipids in the present study (Dänicke et al., 2012) as well as in Pappritz et al. (2011a), which supplemented the same commercial CLA product in comparable dosages (Renner et al., 2012; Kramer et al., 2013). Thus, the bioavailability of CLA in the present study may have been too low to cause more pronounced differences in antioxidative or oxidative status further than the detected decrease in TBARS concentrations of supplemented animals.

However, it needs to be considered that in the current study CLA supplementation started with parturition, but the highest oxidative stress occurred around parturition. Thus, antioxidative properties of CLA may have been more obvious if CLA supplementation started during the dry period to allow sufficient time for accumulation of CLA isomers in body tissues.

Between d 182 and 224 a significant increase of serum hydroperoxides and TBARS was observed in all study groups alongside with significantly decreased FRAP. These results indicate an imbalance between production of radicals and degradation processes. In the current study, CLA was supplemented and incorporated in $4 \mathrm{~kg}$ of transponder-fed concentrate. At d 182, CLA-containing concentrate was removed from the ration and the overall amount of concentrate in the PMR was adjusted to late-lactational milk yield, resulting in a sudden decrease in energy balance (Pappritz et al., 2011b). The altered energy balance led to a rise in serum plasma fatty acids in study cows (Table 3), which may explain the observed increase in oxidative stress.

The significant decline in hydroperoxides between d 224 and 252 shows that the adjustment of the feeding may have caused a temporary effect on metabolism. However, the TBARS concentrations remained elevated until the end of the study despite of low milk yield and positive energy balance at the end of lactation (Pappritz et al., 2011b). In the study of Pedernera et al. (2010), cows with lower milk yield also showed higher oxidative stress than high-yielding cows, but the cause for this also remained unclear.

Next to the significant CLA effect on TBARS concentration, we also noted a trend for animals of the CLA 100 group to exhibit higher bityrosine concentration during period $1(P=0.084)$ than animals in the CON and CLA 50 groups. This may indicate pro-oxidative properties of CLA, as seen under in vitro conditions before (van den Berg et al., 1995). However, this effect of CLA can only be seen as a trend between groups CLA 50 and CLA 100 on d $70(P=0.084)$, and should thus be interpreted carefully.

\section{Primiparous Versus Multiparous Cows}

Multiparous and primiparous animals differed significantly in serum $\alpha$-tocopherol concentrations, with primiparous animals exhibiting constantly higher values than multiparous cows. Preceding the study, primiparous animals were pasture fed for about 3 mo until enrollment for this study at $\mathrm{d}-21$, whereas multiparous animals were kept on pasture only for a short period of 2 to 5 wk between dry off and study start. Pasture feeding results in higher serum vitamin $\mathrm{E}$ concentrations than feeding conserved silage to housed animals (Leiber et al., 2003). Thus, the different feeding strategies before the study may explain the differences in plasma $\alpha$-tocopherol concentrations, as well as $\alpha-\mathrm{T}$ :C, of primiparous and multiparous cows at study start. The higher mean $\alpha-\mathrm{T}$ :C of primiparous than multiparous animals in the present study indicates a better $\alpha$-tocopherol supply in primiparous animals (Herdt and Smith, 1996). However, the mean $\alpha-\mathrm{T}$ :C of primiparous animals compared with multiparous animals remained higher throughout the study, which is presumably attributable to lower milk yield and thereby less transfer of $\alpha$-tocopherol into milk and lower metabolic rate in primiparous than multiparous cows (Jensen et al., 1999).

During period 1, we noted a significant interaction between DIM $\times$ Lact for hydroperoxide concentrations and a trend in terms of TBARS concentrations, revealing less lipid peroxidation products for primiparous compared with multiparous cows, as observed by Albera and Kankofer (2010) previously. During period 2, primiparous animals also exhibited significantly lower hydroperoxide concentrations than multiparous animals. The differences between multiparous and primiparous animals observed in the present trial are likely to be explained by the significantly higher $\alpha$-tocopherol concentrations and the higher $\alpha-T$ : $C$ in serum of primiparous animals, indicating a more effective protection against oxidation (Bowen and Omaye, 1998).

\section{CONCLUSIONS}

Results of the present study revealed no clear effect of supplementation with 50 or $100 \mathrm{~g}$ of a commercial CLA product, containing approximately $12 \%$ of cis-9,trans-11 CLA and trans-10,cis-12 CLA each, on the antioxidative status of dairy cows. However, the significantly lower TBARS concentrations in serum of 
supplemented animals compared with controls indicated a marginal antioxidative effect of CLA in the chosen dosages and route of administration. The difference between multiparous and primiparous animals concerning $\alpha$-tocopherol and oxidative stress parameters, hydroperoxides, and TBARS may indicate that adequate supply of $\alpha$-tocopherol lessens the extent of oxidative stress.

\section{ACKNOWLEDGMENTS}

The authors thank the Deutsche Forschungsgemeinschaft (Berlin, Germany) for financial support (PAK 286/1, RE 819/6-1).

\section{REFERENCES}

Albera, E., and M. Kankofer. 2010. The comparison of antioxidative/ oxidative profile in colostrum, milk and blood of early post-partum cows during their first and second lactation. Reprod. Domest. Anim. 45:e417-e425.

Albera, E., and M. Kankofer. 2011. The comparison of antioxidative/oxidative profile in blood, colostrum and milk of early post-partum cows and their newborns. Reprod. Domest. Anim. 46:763-769.

Alberti, A., L. Bolognini, D. Macciantelli, and M. Caratelli. 2000. The radical cation of n,n-diethyl-para- phenylendiamine: A possible indicator of oxidative stress in biological samples. Res. Chem. Intermed. 26:253-267.

Armstrong, D., and R. Browne. 1994. The analysis of free radicals, lipid peroxides, antioxidant enzymes and compounds related to oxidative stress as applied to the clinical chemistry laboratory. Adv. Exp. Med. Biol. 366:43-58.

Azzi, A., K. J. Davies, and F. Kelly. 2004. Free radical biology-Terminology and critical thinking. FEBS Lett. 558:3-6.

Babior, B. M. 1987. The respiratory burst oxidase. Trends Biochem. Sci. 12:241-243.

Banni, S., E. Angioni, V. Casu, M. P. Melis, G. Carta, F. P. Corongiu, H. Thompson, and C. Ip. 1999. Decrease in linoleic acid metabolites as a potential mechanism in cancer risk reduction by conjugated linoleic acid. Carcinogenesis 20:1019-1024.

Banni, S., E. Angioni, M. S. Contini, G. Carta, V. Casu, G. A. Iengo, M. P. Melis, M. Deiana, M. A. Dessi, and F. P. Corongiu. 1998. Conjugated linoleic acid and oxidative stress. J. Am. Oil Chem. Soc. 75:261-267.

Barrera, G. 2012. Oxidative stress and lipid peroxidation products in cancer progression and therapy. ISRN Oncol. 2012:137289.

Basiricò, L., P. Morera, D. Dipasquale, A. Troscher, A. Serra, M. Mele, and U. Bernabucci. 2015. Conjugated linoleic acid isomers strongly improve the redox status of bovine mammary epithelial cells (BME-UV1). J. Dairy Sci. 98:7071-7082.

Basu, S., A. Smedman, and B. Vessby. 2000. Conjugated linoleic acid induces lipid peroxidation in humans. FEBS Lett. 468:33-36.

Baumgard, L. H., B. A. Corl, D. A. Dwyer, A. Saebo, and D. E. Bauman. 2000. Identification of the conjugated linoleic acid isomer that inhibits milk fat synthesis. Am. J. Physiol. Regul. Integr. Comp. Physiol. 278:R179-R184.

Benzie, I. F. F., and J. J. Strain. 1996. The ferric reducing ability of plasma (FRAP) as a measure of 'antioxidative power': The FRAP assay. Anal. Biochem. 239:70-76.

Bernabucci, U., B. Ronchi, N. Lacetera, and A. Nardone. 2005. Influence of body condition score on relationships between metabolic status and oxidative stress in periparturient dairy cows. J. Dairy Sci. 88:2017-2026.
Bernal-Santos, G., J. W. Perfield 2nd, D. M. Barbano, D. E. Bauman, and T. R. Overton. 2003. Production responses of dairy cows to dietary supplementation with conjugated linoleic acid (CLA) during the transition period and early lactation. J. Dairy Sci. 86:3218-3228.

Bionaz, M., E. Trevisi, L. Calamari, F. Librandi, A. Ferrari, and G. Bertoni. 2007. Plasma paraoxonase, health, inflammatory conditions, and liver function in transition dairy cows. J. Dairy Sci 90:1740-1750

Bobe, G., J. W. Young, and D. C. Beitz. 2004. Invited review: Pathology, etiology, prevention, and treatment of fatty liver in dairy cows. J. Dairy Sci. 87:3105-3124.

Bouwstra, R. J., M. Nielen, J. R. Newbold, E. H. Jansen, H. F. Jelinek, and T. van Werven. 2010a. Vitamin E supplementation during the dry period in dairy cattle. Part II: Oxidative stress following vitamin E supplementation may increase clinical mastitis incidence postpartum. J. Dairy Sci. 93:5696-5706.

Bouwstra, R. J., M. Nielen, J. A. Stegeman, P. Dobbelaar, J. R. Newbold, E. H. Jansen, and T. van Werven. 2010b. Vitamin E supplementation during the dry period in dairy cattle. Part I: Adverse effect on incidence of mastitis postpartum in a double-blind randomized field trial. J. Dairy Sci. 93:5684-5695.

Bowen, H. T., and S. T. Omaye. 1998. Oxidative changes associated with beta-carotene and alpha-tocopherol enrichment of human low-density lipoproteins. J. Am. Coll. Nutr. 17:171-179.

Cadenas, E. 1997. Basic mechanisms of antioxidant activity. Biofactors 6:391-397.

Cantwell, H., R. Devery, M. O'Shea, and C. Stanton. 1999. The effect of conjugated linoleic acid on the antioxidant enzyme defense system in rat hepatocytes. Lipids 34:833-839.

Castañeda-Gutiérrez, E., T. R. Overton, W. R. Butler, and D. E. Bauman. 2005. Dietary supplements of two doses of calcium salts of CLA during transition period and early lactation. J. Dairy Sci 88:1078-1089.

Castillo, C., J. Hernandez, A. Bravo, M. Lopez-Alonso, V. Pereira, and J. L. Benedito. 2005. Oxidative status during late pregnancy and early lactation in dairy cows. Vet. J. 169:286-292.

Chen, Z. Y., P. T. Chan, K. Y. Kwan, and A. Zhang. 1997. Reassessment of the antioxidant activity of conjugated linoleic acids. J. Am. Oil Chem. Soc. 74:749-753.

Chiaradia, E., L. Avellini, F. Rueca, A. Spaterna, F. Porciello, M. T. Antonioni, and A. Gaiti. 1998. Physical exercise, oxidative stress and muscle damage in racehorses. Comp. Biochem. Physiol. B 119:833-836.

Dänicke, S., J. Kowalczyk, L. Renner, J. Pappritz, U. Meyer, R. Kramer, E. M. Weber, S. Doll, J. Rehage, and G. Jahreis. 2012. Effects of conjugated linoleic acids fed to dairy cows during early gestation on hematological, immunological, and metabolic characteristics of cows and their calves. J. Dairy Sci. 95:3938-3953.

Davies, K. J. A., M. E. Delsignore, and S. W. Lin. 1987. Protein damage and degradation by oxygen radicals. J. Biol. Chem. 262:99029907.

Davies, M. J., S. Fu, H. Wang, and R. T. Dean. 1999. Stable markers of oxidant damage to proteins and their application in the study of human disease. Free Radic. Biol. Med. 27:1151-1163.

Drackley, J. K. 1999. Biology of dairy cows during the transition period: The final frontier? J. Dairy Sci. 82:2259-2273.

Frank, J., X. W. D. Chin, C. Schrader, G. P. Eckert, and G. Rimbach. 2012. Do tocotrienols have potential as neuroprotective dietary factors? Ageing Res. Rev. 11:163-180.

Gaál, T., P. Ribiczeyne-Szabo, K. Stadler, J. Jakus, J. Reiczigel, P. Kover, M. Mezes, and L. Sumeghy. 2006. Free radicals, lipid peroxidation and the antioxidant system in the blood of cows and newborn calves around calving. Comp. Biochem. Physiol. B 143:391-396.

Giesy, J. G., M. A. McGuire, B. Shafii, and T. W. Hanson. 2002. Effect of dose of calcium salts of conjugated linoleic acid (CLA) on percentage and fatty acid content of milk fat in midlactation holstein cows. J. Dairy Sci. 85:2023-2029. 
Giulivi, C., N. J. Traaseth, and K. J. Davies. 2003. Tyrosine oxidation products: analysis and biological relevance. Amino Acids 25:227-232.

Goff, J. P., and R. L. Horst. 1997. Physiological changes at parturition and their relationship to metabolic disorders. J. Dairy Sci. 80:1260-1268.

Goff, J. P., and J. R. Stabel. 1990. Decreased plasma retinol, $\alpha$-tocopherol, and zinc concentration during the periparturient period: Effect of milk fever. J. Dairy Sci. 73:3195-3199.

Gornall, A. G., C. J. Bardawill, and M. M. David. 1949. Determination of serum protein by means of the biuret reaction. J. Biol. Chem. 177:751-766.

Ha, Y. L., J. M. Storkson, and M. W. Pariza. 1990. Inhibition of benzo(a)pyrene- induced mouse forestomach neoplasia by conjugated dienoic derivatives of linoleic acid. Cancer Res. 50:10971101.

Halliwell, B. 1996. Commentary: Oxidative stress, nutrition and health. experimental strategies for optimization of nutritional antioxidant intake in humans. Free Radic. Res. 25:57-74.

Halliwell, B., and S. Chirico. 1993. Lipid peroxidation: Its mechanism, measurement and significance. Am. J. Clin. Nutr. 57:715S-725S.

Heidarpour, M., M. Mohri, A. H. Fallah-Rad, F. Dehghan Shahreza, and M. Mohammed. 2012. Oxidative stress and trace elements before and after treatment in dairy cows with clinical and subclinical endometritis. Revue Med. Vet. 163:628-633.

Heinecke, J. W., W. Li, H. L. Daehnke, and J. A. Goldstein. 1993 Dityrosine, a specific marker of oxidation is synthesized by the myeloperoxidase hydrogen peroxide system of human neutrophils and macrophages. J. Biol. Chem. 268:4069-4077.

Herdt, T. H., and J. C. Smith. 1996. Blood-lipid and lactation-stage factors affecting serum vitamin $\mathrm{E}$ concentrations and vitamin $\mathrm{E}$ cholesterol ratios in dairy cattle. J. Vet. Diagn. Invest. 8:228-232.

Hiatt, R., and K. C. Irwin. 1968. Homolytic decomposition of hydroperoxides V: Thermal decompositions. J. Org. Chem. 33:14361441.

Hötger, K., H. M. Hammon, C. Weber, S. Görs, A. Tröscher, R. M. Bruckmaier, and C. C. Metges. 2013. Supplementation of conjugated linoleic acid in dairy cows reduces endogenous glucose production during early lactation. J. Dairy Sci. 96:2258-2270.

Huggins, T. G., M. C. Wells-Knecht, N. A. Detorie, J. W. Baynes, and S. R. Thorpe. 1993. Formation of o-tyrosine and dityrosine in proteins during radiolytic and metal-catalyzed oxidation. J. Biol. Chem. 268:12341-12347.

Hung, T. H., S. F. Chen, T. T. Hsieh, L. M. Lo, M. J. Li, and Y. L. Yeh. 2011. The associations between labor and delivery mode and maternal and placental oxidative stress. Reprod. Toxicol. 31:144150 .

Ip, C., S. F. Chin, and J. A. Scimeca. 1991. Mammary cancer prevention by conjugated dienoic derivate of linoleic acid. Cancer Res. 51:6118-6124

Janero, D. R. 1990. Malondialdehyde and thiobarbituric-acid-reactivity as diagnostic indices of lipid peroxidation and peroxide tissue injury. Free Radic. Biol. Med. 9:515-540.

Jensen, S. K., A. K. Johannsen, and J. E. Hermansen. 1999. Quantitative secretion and maximal secretion capacity of retinol, $\beta$-carotene and $\alpha$-tocopherol into cows' milk. J. Dairy Res. 66:511-522.

Kankofer, M., E. Albera, M. Feldman, N. Gundling, and M. Hoedemaker. 2010. Comparison of antioxidative/oxidative profiles in blood plasma of cows with and without retained fetal placental membranes. Theriogenology 74:1385-1395.

Kramer, R., S. Wolf, T. Petri, D. Von Soosten, S. Dänicke, E. M. Weber, R. Zimmer, J. Rehage, and G. Jahreis. 2013. A commonly used rumen protected conjugated linoleic acid supplement marginally affects fatty acid distribution of body tissues. Lipids Health Dis. 12:96-109.

Krinsky, N. I. 1989. Antioxidant function of carotinoids. Free Radic. Biol. Med. 7:617-635.

LeBlanc, S. J. 2012. Interactions of metabolism, inflammation, and reproductive tract health in the postpartum period in dairy cattle. Reprod. Domest. Anim. 47(Suppl. 5):18-30.
LeBlanc, S. J., T. H. Herdt, W. M. Seymour, T. F. Duffield, and K. E. Leslie. 2004. Peripartum serum vitamin e, retinol, and beta-carotene in dairy cattle and their associations with disease. J. Dairy Sci. 87:609-619.

Ledwozyw, A., J. Michalak, A. Stepien, and A. Kadziolka. 1986. The relationship between plasma triglycerides, cholesterol, total lipids and lipid peroxidation products during human atherosclerosis. Clin. Chim. Acta 155:275-283.

Leiber, F., C. Kunz, H.-R. Wettstein, and M. Kreuzer. 2003. Vitamin E Gehalt der Kuhmilch in Abhängigkeit von der Grasfütterung im Tal und auf der alpinen Weide. Schriftenreihe Institut für Nutztierwissenschaften, ETH Zürich, Zurich, Switzerland.

Leung, Y. H., and R. H. Liu. 2000. trans-10,cis-12-conjugated linoleic acid isomer exhibits stronger oxyradical scavenging capacity than cis-9,trans-11-conjugated linoleic acid isomer. J. Agric. Food Chem. 48:5469-5475.

Livisay, S. A., S. Zhou, C. Ip, and E. A. Decker. 2000. Impact of dietary conjugated linoleic acid on the oxidative stability of rat liver microsomes and skeletal muscle homogenates. J. Agric. Food Chem. 48:4162-4167.

Locher, L., T. Sattler, and T. Wittek. 2011. Relevance, measurement and assessment of the antioxidative status in farm animals. Berl. Munch. Tierarztl. Wochenschr. 124:419-431.

Lohrke, B., T. Viergutz, W. Kanitz, K. Gollnitz, F. Becker, A. Hurtienne, and F. Schweigert. 2004. High milk yield in dairy cows associated with oxidant stress. Online J. Vet. Res. 8:70-78.

Maskos, Z., J. D. Rush, and W. H. Koppenol. 1992. The hydroxylation of tryptophan. Arch. Biochem. Biophys. 296:514-520.

Miller, J. K., E. Brzezinska-Slebodzinska, and F. C. Madsen. 1993. Oxidative stress, antioxidants, and animal function. J. Dairy Sci. $76: 2812-2823$.

Morzel, M., P. Gatellier, T. Sayd, M. Renerre, and E. Laville. 2006. Chemical oxidation decreases proteolytic susceptibility of skeletal muscle myofibrillar proteins. Meat Sci. 73:536-543.

Muller, F. 2000. The nature and mechanism of superoxide production by the electron transport chain: its relevance to aging. J. Am. Aging Assoc. 23:227-253.

Odens, L. J., R. Burgos, M. Innocenti, M. J. VanBaale, and L. H. Baumgard. 2007. Effects of varying doses of supplemental conjugated linoleic acid on production and energetic variables during the transition period. J. Dairy Sci. 90:293-305.

Osorio, J. S., E. Trevisi, P. Ji, J. K. Drackley, D. Luchini, G. Bertoni, and J. J. Loor. 2014. Biomarkers of inflammation, metabolism, and oxidative stress in blood, liver, and milk reveal a better immunometabolic status in peripartal cows supplemented with Smartamine M or MetaSmart. J. Dairy Sci. 97:7437-7450.

Palozza, P., and N. I. Krinsky. 1991. The Inhibition of radical-initiated peroxidation of microsomal lipids by both alpha-tocopherol and beta-carotene. Free Radic. Biol. Med. 11:407-414.

Palozza, P., and N. I. Krinsky. 1992. Beta-carotene and alpha-tocopherol are syngergistic antioxidants. Arch. Biochem. Biophys. 297:184-187.

Pappritz, J., P. Lebzien, U. Meyer, G. Jahreis, R. Kramer, G. Flachowsky, and S. Dänicke. 2011a. Duodenal availability of conjugated linoleic acids after supplementation to dairy cow diets. Eur. J. Lipid Sci. Technol. 113:1443-1455.

Pappritz, J., U. Meyer, R. Kramer, E. M. Weber, G. Jahreis, J. Rehage, G. Flachowsky, and S. Danicke. 2011b. Effects of long-term supplementation of dairy cow diets with rumen-protected conjugated linoleic acids (CLA) on performance, metabolic parameters and fatty acid profile in milk fat. Arch. Anim. Nutr. 65:89-107.

Pedernera, M., P. Celi, S. C. García, H. E. Salvin, I. Barchia, and W. J. Fulkerson. 2010. Effect of diet, energy balance and milk production on oxidative stress in early-lactating dairy cows grazing pasture. Vet. J. 186:352-357.

Politis, I., G. Theodorou, A. D. Lampidonis, A. Kominakis, and A. Baldi. 2012. Short communication: Oxidative status and incidence of mastitis relative to blood $\alpha$-tocopherol concentrations in the postpartum period in dairy cows. J. Dairy Sci. 95:7331-7335. 
Powers, S. K., and M. J. Jackson. 2008. Exercise-induced oxidative stress: Cellular mechanisms and impact on muscle force production. Physiol. Rev. 88:1243-1276.

Qi, X., S. Wu, H. Zhang, H. Yue, S. Xu, F. Ji, and G. Qi. 2011. Effects of dietary conjugated linoleic acids on lipid metabolism and antioxidant capacity in laying hens. Arch. Anim. Nutr. 65:354-365.

Radin, L., M. Simpraga, S. Vince, A. Kostelić, and S. Milinković-Tur. 2015. Metabolic and oxidative status of Saanen goats of different parity during the peripartum period. J. Dairy Res. 82:426-433.

Rahmanto, A. S., P. E. Morgan, C. L. Hawkins, and M. J. Davies. 2010. Cellular effects of peptide and protein hydroperoxides. Free Radic. Biol. Med. 48:1071-1078.

Rammell, C. G., B. Cunliffe, and A. J. Kieboom. 1983. Determination of alpha-tocopherol in biological specimens by high-performance liquid chromatography. J. Liq. Chromatogr. 6:1123-1130.

Renner, L., J. Pappritz, R. Kramer, S. Kersten, G. Jahreis, and S. Dänicke. 2012. Fatty acid profile and proliferation of bovine blood mononuclear cells after conjugated linoleic acid supplementation. Lipids Health Dis. 11:63-70.

Rice-Evans, C. A., A. T. Diplock, and M. C. R. Symons. 1991. Techniques in Free Radical Research. Elsevier Science, Amsterdam, the Netherlands.

Risérus, U. 2002. Supplementation with conjugated linoleic acid causes isomer-dependent oxidative stress and elevated C-reactive protein: A potential link to fatty acid-induced insulin resistance. Circulation 106:1925-1929.

Sadri, H., S. Dänicke, U. Meyer, J. Rehage, J. Frank, and H. Sauerwein. 2015. Tocopherols and tocotrienols in serum and liver of dairy cows receiving conjugated linoleic acids or a control fat supplement during early lactation. J. Dairy Sci. 98:7034-7043.

Santos-Zago, L. F., A. P. Botelho, and A. C. de Oliveira. 2007. Supplementation with commercial mixtures of conjugated linoleic acid in association with vitamin $\mathrm{E}$ and the process of lipid autoxidation in rats. Lipids 42:845-854.

Scherer, N. M., and D. W. Deamer. 1986. Oxidative stress impairs the function of sarcoplasmic reticulum by oxidation of sulfhydryl groups in the Ca 2+-ATPase. Arch. Biochem. Biophys. 246:589601.

Sies, H. 1993. Strategies of antioxidant defense. Eur. J. Biochem. 215:213-219.

Stewart, B. W. 1994. Mechanisms of apoptosis: Integration of genetic, biochemical, and cellular indicators. J. Natl. Cancer Inst. 86:12861296.

Tatarková, Z., P. Kaplan, M. Matejovicova, and J. Lehotský. 2005. Effect of ischemia and reperfusion on protein oxidation in isolated rabbit hearts. Physiol. Res. 54:185-191.

Turk, R., D. Juretic, D. Geres, N. Turk, V. Simeon-Rudolf, B. Reki, and A. Svetinaa. 2005. Oxidative stress in dairy cows-serum paraoxonase activity related to hepatomegaly. Croat. Chem. Acta $78: 375-378$.

van den Berg, J. J. M., N. E. Cook, and D. L. Tribble. 1995. Reinvestigation of the antioxidant properties of conjugated linoleic acid. Lipids 30:599-605.

Weiss, W. P., J. S. Hogan, K. L. Smith, D. A. Todhunter, and S. N Williams. 1992. Effect of supplementing periparturient cows with vitamin $\mathrm{E}$ on distribution of $\alpha$-tocopherol in blood. J. Dairy Sci. $75: 3479-3485$.

Yu, L. 2001. Free radical scavenging properties of conjugated linoleic acids. J. Agric. Food Chem. 49:3452-3456.

Zhang, H. J., Y. D. Tian, Y. M. Guo, and J. M. Yuan. 2008. Dietary conjugated linoleic acid improves antioxidant capacity in broiler chicks. Br. Poult. Sci. 49:213-221. 